\title{
Antiepileptic and antiamnesic effect of carbamazepine in experimental limbic epilepsy
}

\author{
CATHERINE A HAWKINS, JANE MELLANBY, J BROWN \\ From the Department of Experimental Psychology, University of Oxford, Oxford, UK
}

SUMMARY Carbamazepine $(20 \mathrm{mg} / \mathrm{kg}, 40 \mathrm{mg} / \mathrm{kg}$ or $60 \mathrm{mg} / \mathrm{kg}$ ) given three times a day, has been demonstrated to have a significant anti-epileptic effect in rats with chronic limbic epilepsy induced by injecting tetanus toxin bilaterally into their hippocampi. This effect involved a reduction in the maximum number of fits occurring on one day, and with the highest dose, a significant reduction in the total number of fits. In a pilot experiment in which continuous EEG records were obtained throughout the syndrome, it appeared that the effect of carbamazepine was to reduce the proportion of EEG seizure discharges which lead to overt motor fits. With the higher drug dose plasma levels of carbamazepine were maintained around $2 \mu \mathrm{g} / \mathrm{ml}$. This experimental epilepsy produces enduring deficits in the rats' memories for a light-discrimination task in a Y-maze learned before induction of epilepsy ( 8 weeks after initial learning). If the rats are dosed with carbamazepine during their epilepsy this memory deficit is abolished.

Recent work in this laboratory has exploited an animal model of complex partial seizures produced by injection of minute doses of the exceptionally toxic protein, tetanus toxin, into the hippocampus of rats. The toxin produces chronic focal epilepsy, probably by its ability to block the release of the inhibitory transmitter, gamma-aminobutyric acid. ${ }^{2}$ This causes a chronic epileptiform syndrome in which the rats have intermittent myoclonic seizures, electroencephalographic signs of focal epilepsy and show a wide range of behavioural abnormalities. We have a remarkably complete life-history of this syndrome, obtained from continuous EEG and video records over periods of several weeks. The model has a number of advantages over other experimentally-induced chronic epilepsies. In particular, the toxin appears to produce a specific pharmacological lesion since control animals simlarly injected with neutralised toxin do not develop the epilepsy and also because the effects of the toxin occur without any associated gross pathological changes at the site of injection. ${ }^{3}$ Furthermore, while the epilepsy is chronic, since it lasts for several weeks, it is at least partially reversible in that the

Address for reprint requests: Dr J Mellanby, Dept of Experimental Psychology, South Park Rd, Oxford OX1 3UK, UK.

Received 10 April 1984 and in revised form 3 September 1984. Accepted 22 September 1984 animals eventually stop having fits and the obvious epileptiform abnormalities in their EEGs disappear. ${ }^{4}$ This reversibility allows us to distinguish between behavioural effects of ongoing epilepsy and sequelae to previous epilepsy.

We have shown that this epilepsy causes deficits, which outlast ongoing epilepsy, in both the ability of the animals to remember tasks which they had learned before they were epileptic and in their ability to learn new tasks. ${ }^{56}$ This finding may be relevant to the important clinical question of whether the intellectual impairment, including problems in learning and memory, seen in patients with complex partial seizures ${ }^{78}$ is a result of the epilepsy per se or is produced by antiepileptic medication or adverse environmental factors.

We have also recently shown that the extent of memory loss in the epileptic animals roughly correlates with the severity of the epileptic syndrome, ${ }^{9}$ in particular with how many fits the animals have had and with the maximum number of fits which have occurred in one day. This could be considered to give quantitative confirmation in the animal model to the clinical belief ${ }^{10}$ that there is an association between number of fits and subsequent intellectual impairment in patients with complex partial seizures.

From the experimental data we have collected so far we believe that the tetanus toxin-induced epilepsy provides a particularly useful model for the 
study of the relationship between complex partial seizures and behaviour. An obvious question in the attempt to validate this model is whether the seizures can be controlled by antiepileptic medication of the sort which is successful clinically in complex partial seizures. If such drugs can control fits in the experimental epilepsy then it should be possible to investigate further the relationship between fits and behavioural impairment. In the present paper we report a quantitative assessment of the antiepileptic effect of the drug carbamazepine and of its effect on memory in normal and epileptic rats. Carbamazepine was selected as the first drug to study with this animal model because it is widely considered clinically to be the drug of choice in the treatment of complex partial seizures. ${ }^{11-13}$

\section{Materials and methods}

Four separate experiments to investigate the effect of carbamazepine on the experimental epilepsy were carried out: in the first, only the antiepileptic effect of the drug was studied; in the next two ( 2 and 3 ) the rats were first trained in a Y-maze, then made epileptic and the antiepileptic effect of carbamazepine studied as before, and then 3-4 weeks after fits and drug treatment had stopped, the animals' memories for the Y-maze task were tested. In experiments 2 and 3, two additional groups of control (nonepileptic) rats were trained in the Y-maze and half were treated with carbamazepine and half with vehicle in the same way as for the epileptic rats. Their memories were then also tested at the same time as the epileptic rats were tested. In experiment 4 the effect of carbamazepine on the frequency of electroencephalographically recorded seizure discharges was investigated. Experiment 5 involved determining blood levels of control rats dosed either at $40 \mathrm{mg} /$ $\mathrm{kg}$ or $60 \mathrm{mg} / \mathrm{kg}$. (These measurements were not carried out on the actual animals used in the antiepileptic and memory experiments because the operation for the implantation of the cannula would interfere with the recording of fits and the anaesthesia would be likely to influence their fre- quency.) Table 1 shows a summary of the details of experiments $1-5$.

Tetanus toxin A tetanus toxin preparation containing $6 \times$ $10^{6}$ mouse LD $50^{\prime} \mathrm{s} / \mathrm{mg}$ was kindly provided by $\operatorname{Dr} \mathrm{RO}$ Thomson of the Wellcome Research Laboratories. It was dissolved in $0.05 \mathrm{M}$ sodium phosphate buffer $(\mathrm{pH} \mathrm{7.0)}$ containing $0.2 \%$ gelatin $w / v$. Dilutions were made in this mixture. The toxicity of the solutions was assayed ${ }^{14}$ on each day that injections were made into the brains of rats. Control animals received the same amount of the gelatin phosphate buffer alone.

Animals Male Sprague Dawley rats weighing 300-450 g were used (and in one experiment, females weighing 250 $300 \mathrm{~g}$ ).

Light-discrimination Task The rats were trained to run to the lit and safe arm of a Y-maze to escape electric shock $(0.6 \mathrm{~mA})$ applied to the feet. ${ }^{15}$ An error was scored if the rat entered 3 (or 4 ) paws into the wrong arm. The time between the start of one trial and the start of the next trial is was $30 \mathrm{~s}$. The animals were trained in one session to a $\overrightarrow{0}$ criterion of 10 consecutive correct choices. On the basis of their initial training scores the rats were divided into four $\vec{\omega}$ groups matched so that the number of trials taken to reach $\mathrm{O}$ criterion and the number of errors made on initial training (and their variance) were similar. The rats' memories were tested by re-training the rats 8 weeks later in the same task $\vec{\infty}$ to the same criterion. The results are expressed in terms op or the saving per cent made on re-training in the number of trials and number of errors:

$$
\text { Saving } \%=\frac{\text { initial score }- \text { retraining score }}{\text { initial score }+ \text { retraining score }} \times 100
$$

Operative Procedure The rats were anaesthetised with Equithesin $3 \mathrm{ml} / \mathrm{kg}$ (containing $81 \mathrm{ml}$ sodium pentoba bitone, $198 \mathrm{ml}$ propylene glycol, $50 \mathrm{ml}$ enthanol, $21 \mathrm{f} \cdot \vec{\bullet}$ chloral hydrate, $10.6 \mathrm{~g} \mathrm{MgSO}$ made up to $500 \mathrm{ml}$ wit o distilled water). The rats were then placed in a Kopf stereotaxic instrument. Injections of toxin $(2 \times 0.4 \mu \mathrm{l}$ bilaterally of $1 \mu \mathrm{l}$ unilaterally in the case of rats with implanted electrodes) were made from a $10 \mu \mathrm{l}$ Hamilton syringe mounted in the instrument's microinjection unit. ٌ The injection was made over a period of one minute, and $\Phi$ the needle was then left in place for a further 2 minutes

Table 1 Summary of experimental design

\begin{tabular}{|c|c|c|c|c|c|c|c|c|c|}
\hline \multirow[t]{3}{*}{ Experiment } & \multirow{2}{*}{\multicolumn{2}{|c|}{$\begin{array}{l}\text { No. of rats used for testing } \\
\text { antiepileptic effect }\end{array}$}} & \multirow{3}{*}{$\begin{array}{l}\text { Dose of CBZ } \\
(3 \text { times/day) } \\
\text { mg/kg }\end{array}$} & \multirow{3}{*}{$\begin{array}{l}\text { Vehicle for } \\
\text { CBZ }\end{array}$} & \multirow{3}{*}{$\begin{array}{l}\text { Hours filmed } \\
\text { (or recorded) } \\
\text { each day }\end{array}$} & \multicolumn{4}{|c|}{ No. of rats used for memory testing } \\
\hline & & & & & & \multicolumn{2}{|l|}{ Control } & \multicolumn{2}{|c|}{ Epileptic } \\
\hline & Epileptic - CBZ & Epileptic $+C B Z$ & & & & $-C B Z$ & $+C B Z$ & $-C B Z$ & $+3 \mathrm{Cb}$ \\
\hline $\begin{array}{l}\text { Video films of motor } \\
1\end{array}$ & $\begin{array}{l}\text { rfits } \\
8\end{array}$ & 8 & 20 & $\begin{array}{l}\text { carboxy-methyl } \\
\text { cellulose }\end{array}$ & 12 & & & one & $\frac{8}{3}$ \\
\hline 2 & 6 & 7 & 40 & $\begin{array}{l}\text { Tragacanth } \\
\text { Ciba-Geigy }\end{array}$ & 24 & 8 & 8 & 6 & 글 \\
\hline 3 & 12 & 10 & 60 & $\begin{array}{l}\text { Tragacanth } \\
\text { Ciba-Geigy }\end{array}$ & 24 & 12 & 12 & 11 & 空 \\
\hline $\begin{array}{l}\text { EEG records and video } \\
4\end{array}$ & 4 & 6 & 20 & $\begin{array}{l}\text { carboxyl-methyl } \\
\text { cellulose }\end{array}$ & 24 & & & one & N \\
\hline$\underset{5}{\text { Blood levels of CBZ }}$ & $\begin{array}{l}\text { Controls } \\
4 \\
3\end{array}$ & - & $\begin{array}{l}40 \\
60\end{array}$ & $\begin{array}{l}\text { Tragacanth } \\
\text { Ciba-Geigy }\end{array}$ & $\mathbf{n} / \mathbf{a}$ & & & & $\begin{array}{l}\text { ల్ } \\
\text { N } \\
\end{array}$ \\
\hline
\end{tabular}




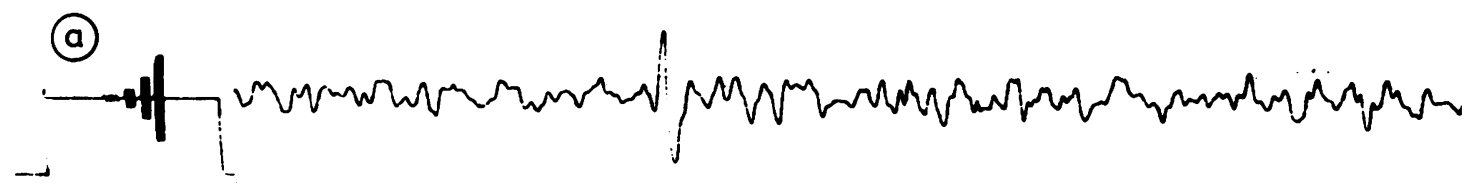

(b)

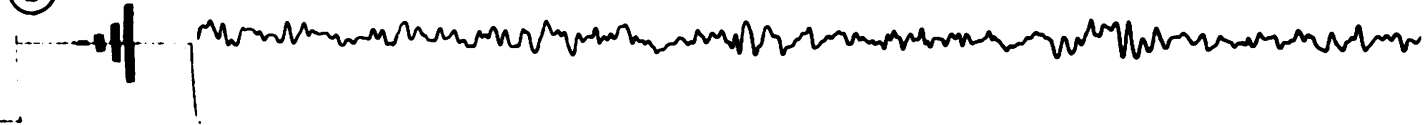
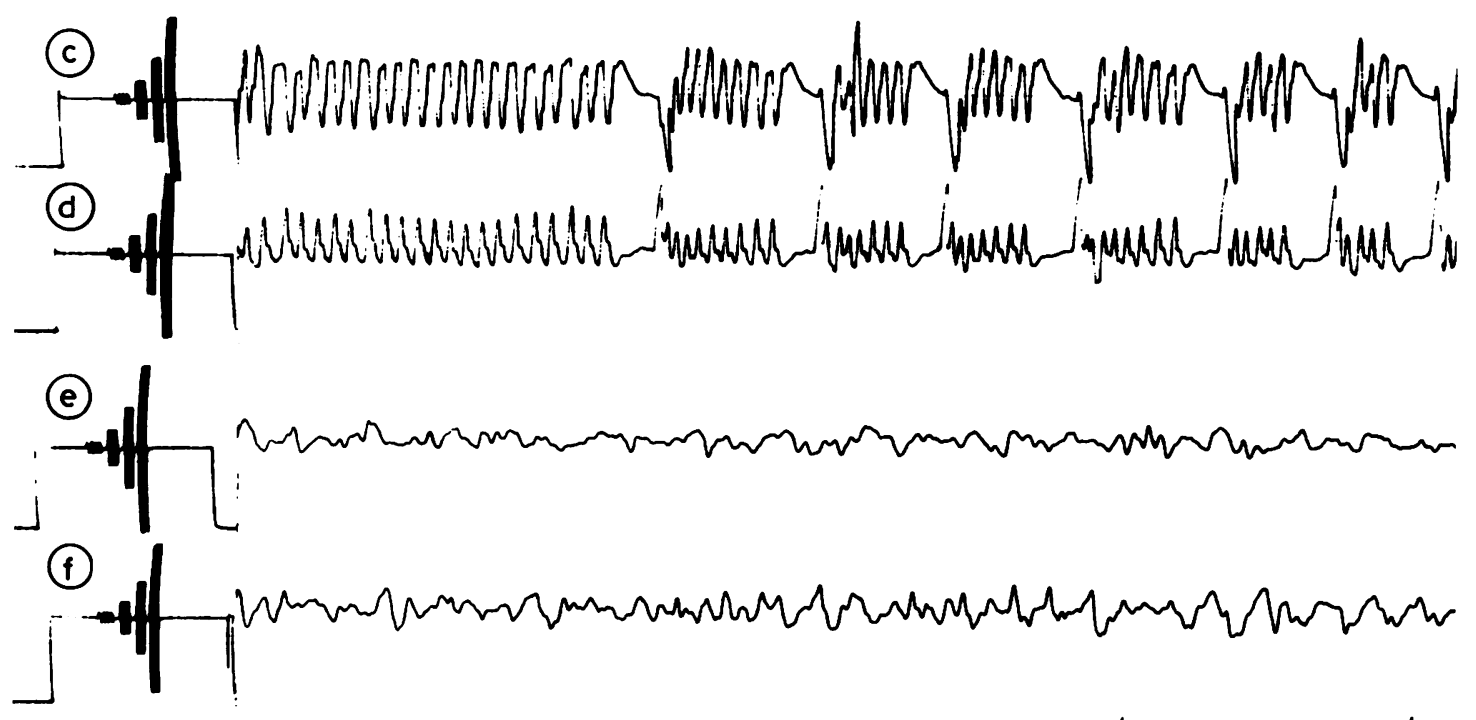

Fig 1 Electroencephalographic records from three epileptic rats. Each rat had received tetanus toxin ( 6 mouse $L D_{s 0}$ ) unilaterally into the hippocampus, one week previously. Each pair of traces $(a, b ; c, d ; e, f)$ is recorded from the injected (top) and uninjected (lower) hippocampus. The record from the second rat $(c, d)$ shows the electrical activity during the start of $a$ motor fit. Calibrations: The 4 vertical bars at the beginning of each trace represent $100 \mu \mathrm{V}, 250 \mu \mathrm{V}, 500 \mu \mathrm{V}$ and $1000 \mu \mathrm{V}$ (reading from left to right). The horizontal bar represents $5 \mathrm{~s}$.

before withdrawal. Injection into the ventral hippocampus was made according to De Groot's Atlas of Neuroanatomy, ${ }^{16}$ with co-ordinates anterior $+3.0 \mathrm{~mm}$, lateral $\pm 4.8 \mathrm{~mm}$ and vertical $-2.0 \mathrm{~mm}$.

Implantation of recording electrodes and recording of the hippocampal electrical activity.

Bipolar electrodes were made of double twisted diamelcoated stainless steel, $0.015 \mathrm{~cm}$ diameter. The tips of the two poles were separated from each other by $1 \mathrm{~mm}$. Tetanus toxin was injected at the same operation as that in which the electrodes were implanted. The toxin was injected first and the electrode was placed stereotoxically $0.5 \mathrm{~mm}$ dorsal to the site of toxin injection. A second electrode was implanted in the corresponding position on the opposite side of the brain. The electrodes plus earth wire were wired into a plug which was fixed to the skull of the rat with dental cement.
The rats were housed separately in open-topped cages with high sides. The day after operation the plugs on the rats' heads were connected to a Beckman 'Accutrace' 8 channel EEG recorder. Recordings were taken continuously for the next 7 weeks, or for as long as the plug remained on the rats' head, apart from occasional periods overnight when the rat became accidentally unplugged.

Within a few days of the injection of the toxin, characteristic seizure discharges were recorded from the hippocampi of these rats. These discharges were of 20-200 s duration, and occurred at frequencies of up to 5 per hour. A typical seizure discharge is illustrated in fig 1 .

\section{Filming of rats}

The rats without implanted electrodes were housed four to a cage, and were marked with dye so that they could be distinguished easily on film. The rats were filmed continuously using a Link electronic camera and time-lapse video 
recorder (National TL VTR NV-8030). During the hours of darkness (21.00-9.00) filming took place using an infra red source and an infra red sensitive camera tube. The tapes were played back and the number of seizures experienced by each rat was recorded. A fit was defined as an epileptic episode in which the rat could be seen to rear onto its hindlimbs with myolonic jerking of the forelimbs.

The rats with implanted electrodes were also filmed in a similar manner. Two cameras were used-one to record the behaviour of the rats and the second to film the EEG record. A split screen system allowed the two pictures to be viewed simultaneously on one monitor. These tapes were played back to assess whether a motor fit occurred during the seizure discharges.

\section{Administration of carbamazepine}

Carbamazepine or "vehicle" was administered orally to the rats three times daily at $9.00,15.00$ and 21.00 hours. In the experiment in which the rats had electrodes implanted, and in experiment 1 , carbamazepine was suspended in $0.5 \%$ carboxy-methyl-cellulose at a concentration of $20 \mathrm{mg} / \mathrm{ml}$ and a dose of $20 \mathrm{mg} / \mathrm{kg}$ was given. In experiments 2 and 3 , the rats were dosed with carbamazepine $(20 \mathrm{mg} / \mathrm{ml})$ in a commercially available suspension (Tegreto syrup), kindly provided by Ciba-Geigy, Horsham. This change was instituted because the rats apparently disliked the carboxy-methyl-cellulose suspension, but were fairly willing to take the Tegretol syrup.

The rats were given their first dose of drug or vehicle as soon as the first fit or seizure discharge had been observed. Dosing continued until one week had elapsed since any rat had had a fit. The drug was administered using a $5 \mathrm{ml}$ syringe. The end was inserted into the rat's mouth and the drug was squirted out. Rough allowance was made for any

a

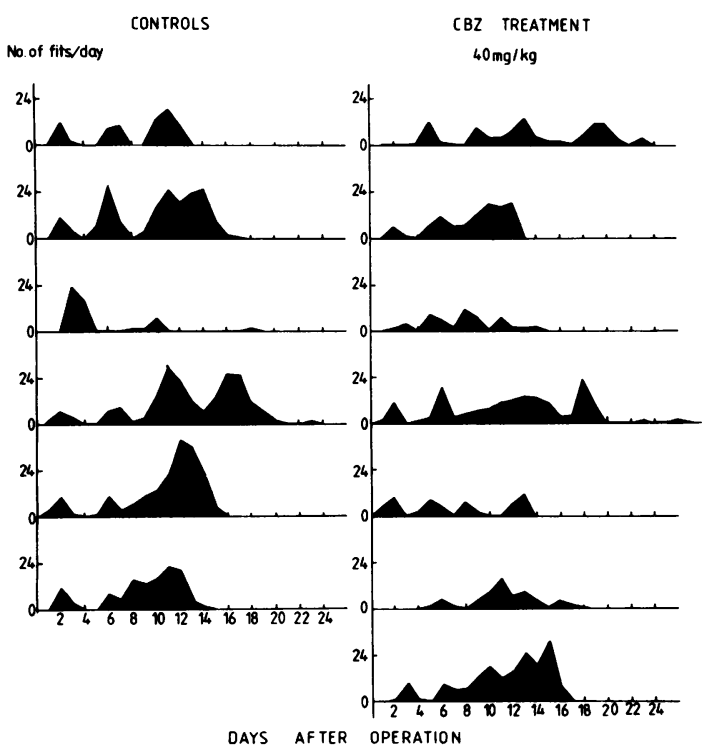

drug which the rat dribbled or spat out. On those occasions that a rat was hyper-reactive and difficult to handle, it was $\bar{Z}$ placed into a black cloth bag which calmed it, and then just $\mathbb{D}$ the head was allowed to protrude through a hole in the $\overline{\bar{O}}$ bag. This procedure facilitated oral administration of the drug.

Blood levels of carbamazepine

Ten male Sprague Dawley rats (about $500 \mathrm{~g}$ ) were cannu-

b

CONTROLS

CBZ TREATMENT

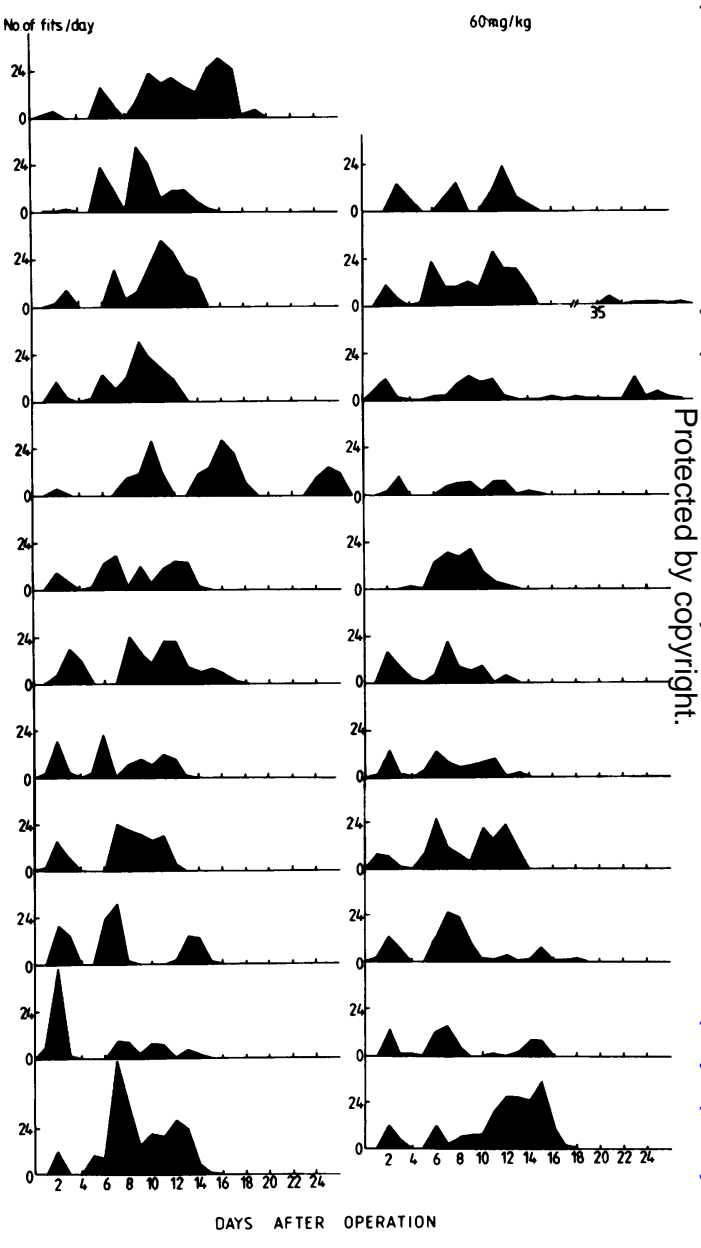

Fig 2 Life history of the epilepsy and the effect of carbamazepine. (a) Experiment 2-with $40 \mathrm{mg} / \mathrm{kg}$ carbamazepine, (b) Experiment 3-with $60 \mathrm{mg} / \mathrm{kg}$ carbamazepine. Each graph represents the futs experienced by one rat. They are plotted as the total fits recorded on each $\bar{N}$ day after the operation at which epilepsy was induced. The $\mathrm{G}$ fits were assessed from time-lapse video records (see Methods). 
Antiepileptic and antiamnesic effect of carbamazepine in experimental limbic epilepsy

Table 2 Effects of carbamazepine (CBZ) on frequency of motor fits

\begin{tabular}{|c|c|c|c|c|c|c|c|c|c|c|}
\hline Experiment & $\begin{array}{l}\text { Dose of } C B Z \\
\mathrm{mg} / \mathrm{kg}\end{array}$ & $n$ & $\begin{array}{l}\text { Length of } \\
\text { Syndrome } \\
\text { (days) }\end{array}$ & $\begin{array}{l}\text { Days with } \\
\text { fits }\end{array}$ & $\begin{array}{l}\text { Total motor } \\
\text { fits in } \\
\text { daytime }\end{array}$ & & $\begin{array}{l}\text { Total motor } \\
\text { fits over } \\
24 \mathrm{hr}\end{array}$ & & $\begin{array}{l}\text { Maximum no. } \\
\text { of motor fus } \\
\text { on any one day }\end{array}$ & \\
\hline $1^{*}$ & $\begin{array}{r}0 \\
20\end{array}$ & $\begin{array}{l}8 \\
8\end{array}$ & $\begin{array}{l}13 \cdot 4 \pm 4 \cdot 7 \\
12 \cdot 5 \pm 2 \cdot 6\end{array}$ & $\begin{array}{l}9.1 \pm 0.9 \\
9.9 \pm 1.6\end{array}$ & $\begin{array}{r}102.0 \pm 21.9 \\
56.0 \pm 12.2\end{array}$ & N.S. & - & & $\begin{array}{l}23 \cdot 3 \pm 2 \cdot 7 \\
13 \cdot 6 \pm 1 \cdot 6\end{array}$ & $p<0.02$ \\
\hline 2 & $\begin{array}{r}0 \\
40\end{array}$ & $\begin{array}{l}6 \\
7\end{array}$ & $\begin{array}{l}15 \cdot 5 \pm 1 \cdot 5 \\
15 \cdot 1 \pm 1.4\end{array}$ & $\begin{array}{l}11.7 \pm 1.8 \\
12.9 \pm 1.2\end{array}$ & $\begin{array}{l}80.8 \pm 13.8 \\
43.9 \pm 3.8\end{array}$ & $p<0.05$ & $\begin{aligned} 135 & \pm 23.5 \\
99.1 & \pm 17.7\end{aligned}$ & N.S. & $\begin{array}{l}26 \cdot 6 \pm 2.9 \\
16 \cdot 6 \pm 2 \cdot 2\end{array}$ & $p<0.05$ \\
\hline 3 & $\begin{array}{r}0 \\
60\end{array}$ & $\begin{array}{l}12 \\
10\end{array}$ & $\begin{array}{l}15 \cdot 3 \pm 1.6 \\
14.8 \pm 1.7\end{array}$ & $\begin{array}{l}11.4 \pm 0.6 \\
11 \cdot 3 \pm 1.0\end{array}$ & $\begin{array}{l}79.1 \pm 7.9 \\
47.7 \pm 4.7\end{array}$ & $\mathrm{p}<0.05$ & $\begin{array}{r}152 \pm 13.2 \\
92.0 \pm 10.7\end{array}$ & $\mathrm{p}<0.01$ & $\begin{array}{l}29.8 \pm 2.1 \\
19.2 \pm 2.1\end{array}$ & $\mathrm{p}<0.01$ \\
\hline $3^{+}$ & $\begin{array}{r}0 \\
60\end{array}$ & $\begin{array}{r}11 \\
9\end{array}$ & $\begin{array}{l}15 \cdot 5 \pm 1 \cdot 7 \\
13.6 \pm 1.3\end{array}$ & $\begin{array}{l}11.5 \pm 0.6 \\
10.8 \pm 1.0\end{array}$ & $\begin{array}{l}76 \cdot 8 \pm 8 \cdot 3 \\
46.2 \pm 5 \cdot 0\end{array}$ & $p<0.05$ & $\begin{array}{c}152 \pm 14.3 \\
93.2 \pm 11.8\end{array}$ & $p<0.01$ & $\begin{array}{l}29 \cdot 3 \pm 2.3 \\
19.9 \pm 2 \cdot 2\end{array}$ & $p<0.01$ \\
\hline
\end{tabular}

(The Carbamazepine was given orally 3 times daily. Length of syndrome is the time between the days on which the first and last fits occurred. All the values are given \pm standard errors of the mean. The $p$ values are derived from the student's $t$ test.)

*The rats were filmed continuously except in Experiment 1 where they were only filmed for $12 \mathrm{~h}$ per day (between 09.00 and 21.00 ) when the lights were on. In experiment 1 half of the animals were male and half female; in experiments 2 and 3 they were all male. The figures in $3^{+}$exclude 2 rats which were sacrificed before the memory measurements were made and which are therefore not present in the data in table 3 .

lated through the jugular vein into the right atrium with the proximal end running subcutaneously to emerge at the back of the neck. The operation was performed under Equithesin anaesthesia. The intravenous part of the cannula was made of silastic tubing (0.02 in. internal diameter, 0.037 in. external diameter, Dow Corning Corp.), and this was joined by a stainless steel connector ( 22 gauge) to Tygon tubing ( 0.02 in. i.d., thick walled, Technicon).

Carbamazepine was administered at a dose of either 40 $\mathrm{mg} / \mathrm{kg}$ or $60 \mathrm{mg} / \mathrm{kg}$ three times a day $(09.00,15.00,21.00)$ for 1 week before the insertion of the cannula, and throughout the experiment. Blood samples $(0.4 \mathrm{ml}$ each time) were taken immediately before each dose, and 1 hour later. In addition samples were taken at 02.00 and 05.00. The blood was replaced with an equal volume of heparinised saline $(0.9 \%$ saline containing 100 i.u. heparin/ml). Samples were taken until the cannulae blocked. The samples were centrifuged and the plasma supernatant stored at $4^{\circ} \mathrm{C}$ until assay. The carbamazepine assays were carried out by Dr John Keenan, Department of Clinical Biochemistry, John Radcliffe Hospital, Oxford, using the Elisa Syva-Syntex enzyme-linked absorbent assay.

\section{Results}

Antiepileptic effect of carbamazepine on motor fits In these experiments $(1,2,3)$ the effect of administering carbamazepine orally three times a day $(09.00,15.00,21.00$ hours) to rats made epileptic with intrahippocampally injected tetanus toxin was studied. In the first experiment described, there were eight rats dosed with the drug (at $20 \mathrm{mg} / \mathrm{kg}$ ) and eight control rats (dosed with the vehicle for the carbamazepine). All sixteen rats were filmed for the 12 hours of light for 4 weeks with time-lapse videorecording. In Experiments 2 and $3,40 \mathrm{mg} / \mathrm{kg}$ and $60 \mathrm{mg} / \mathrm{kg}$ of carbamazepine respectively were used. The rats were filmed continuously in bright light for 12 hours of each day followed by 12 hours in infra-

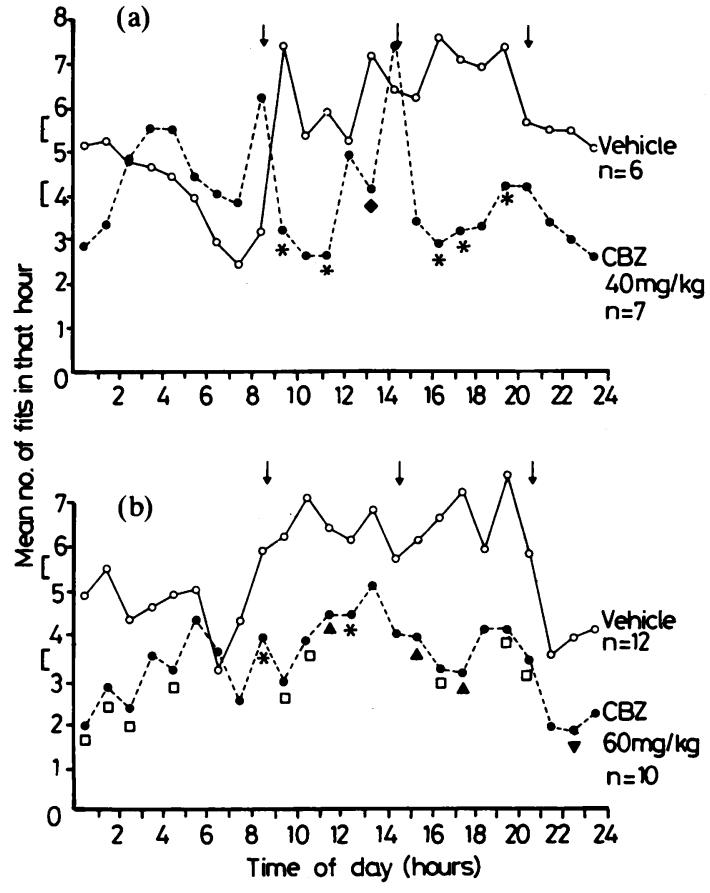

Fig 3 The time-course of the antiepileptic effect of carbamazepine. (a) Experiment with $40 \mathrm{mg} / \mathrm{kg}$ carbamazepine, (b) Experiment with $60 \mathrm{mg} / \mathrm{kg}$ carbamazepine. The drug was given orally three times a day at the times indicated on the graphs by vertical arrows. $N=$ number of rats in the group. The number of fits that each rat experienced throughout the weeks of the epileptiform syndrome have been expressed in terms of the number of fits which occurred during each hour of the day. The means were then calculated for the group of rats for each hour. 
red light. The number and time of occurrence of fits was assessed from watching the videotapes.

In fig 2 the "life history" of the epilepsy experienced by each rat in Experiments 2 and 3 is illustrated, showing the number of motor fits per day throughout the period that filming was carried out. It can be seen that all but three of the rats had their first fit within 3 days of the operation. A striking feature of the profiles is the apparently cyclical waxing and waning of the fit frequency. Figures $2 a$ and $2 b$ show the histories on the left of the controlepileptic animals and on the right of the carbamazepine-treated animals (fig $2 \mathrm{a}, 40 \mathrm{mg} / \mathrm{kg}$ and fig $2 \mathrm{~b}, 60 \mathrm{mg} / \mathrm{kg}$ carbamazepine). The overall impression is that while there are somewhat fewer fits in the treated animals, the general timing of the occurrence of fits is similar in both groups. Quantitative analysis of the data confirms this similarity. Thus the mean number of "peaks" in the fit frequency record is $3.8 \pm 0.8(\mathrm{SD})$ in the controls and $4.0 \pm 0.7(\mathrm{SD})$ in the treated rats, the length of syndrome (time between first and last fit) and the number of days on which fits were seen are all similar (see table 2).

The moderate anticonvulsant effect of the carbamazepine is shown by the data given in table 2 . It can be seen that while there is apparently some reduction in the total number of fits with $20 \mathrm{mg} / \mathrm{kg}$ and $40 \mathrm{mg} / \mathrm{kg}$ of carbamazepine this does not reach statistical significance. The difference is however significant with $60 \mathrm{mg} / \mathrm{kg}(\mathrm{p}<0.02)$. What is statistically significant in all three experiments is that the maximum number of fits which a rat experienced on any one day (the maximum "peak height" in fig 2) is reduced.

The three experiments described were carried out separately and there are a number of important differences (apart from dose of carbamazepine) between experiment 1 and experiments 2 and 3 . In particular, the data for Experiment 1 refer only to the 12 hours when the lights were on, whereas 2 and 3 involved continuous filming throughout the 24 hours. The data from the three experiments can be combined therefore if only the daylight data for experiments 2 and 3 are used. When this is done, the three control groups are found not to differ significantly from each other and can therefore be combined. Analysis of variance was carried out to determine the level of significance of the difference between the total number of (daytime) fits experienced by the carbamazepine-treated and the vehicle-treated epileptic rats, and then to see whether there was a significant dose-effect. A 2-factor analysis of variance with factors of drug and dose nested within drug gave a main effect of drug (df: $1,47 F=13.60 ; p<0.01$ ) and a non-significant dose-effect. (A slightly different statistical approach does produce a significant relationship with dose. A one-way analysis of variance with polynomial on dose yields a significant linear relationship: df: 1, 47; F $=11.81 ; p<0.01$. However this linearity depends mainly on the large difference between the vehicle group and the $20 \mathrm{mg} / \mathrm{kg}$ group, and while there is more effect with 40 and $60 \mathrm{mg} / \mathrm{kg}, 40$ and $60 \mathrm{mg} / \mathrm{kg}$ are not different from each other.)

Time-course of the effect of carbamazepine In fig 3 (a and b) the fit frequency over the 4 week filming period for all the rats in each epileptic group, expressed in terms of the hour of day at which they occurred, is related to the time at which the carbamazepine was administered. With $40 \mathrm{mg} / \mathrm{kg}$ it can be seen that while the drug caused a rapid reduction in seizure frequency, the frequency climbed back towards the control level 4-5 hours after the dose. With $60 \mathrm{mg} / \mathrm{kg}$ the drug maintained the seizure level below that of the controls virtually throughout the 24 hrs.

It appears that in the undosed animals there may be a diurnal rhythm in fit frequency, more fits occurring during the hours of light than during the dark

Plasma levels of carbamazepine (Experiment 5) Non-epileptic rats were given carbamazepine 0 exactly as in the epilepsy experiments for one week and then were implanted with a cannula in the external jugular vein. The dosing was continued ang blood samples for carbamazepine assay were witho drawn at intervals. Figure 4 demonstrates that blood $\vec{\oplus}$

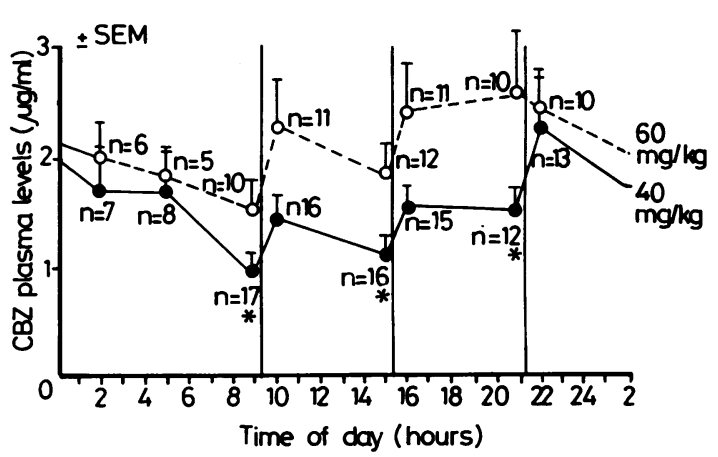

Fig 4 Plasma levels of carbamazepine. Carbamazepine was administered orally three times a day, at the doses indicated, for one week. The external jugular vein of the rats was then cannulated, dosing continued as before, and blood samples withdrawn before and after each dose over a period of $3-4$ days. The results shown are derived from 4 rats given $40 \mathrm{mg} / \mathrm{kg}$ and 3 rats given $60 \mathrm{mg} / \mathrm{kg}$. The values for the different times have been averaged and the points represent the means (+SEM). The n for each point indicates the number of blood samples. 
Table 3 Effect of carbamazepine (CBZ) on frequency of seizure discharges and motor fits

\begin{tabular}{llllll}
\hline & $n$ & $\begin{array}{l}\text { Total seizure } \\
\text { discharges }\end{array}$ & Total motor fits & $\begin{array}{l}\text { \% of Seizure } \\
\text { discharges which } \\
\text { were accompanied }\end{array}$ & $\begin{array}{l}\text { Maximum no. of } \\
\text { seizure discharges } \\
\text { on any one day }\end{array}$ \\
\hline Vehicle & 4 & $\begin{array}{l}864 \pm 278 \\
\text { CBZ }(20 \mathrm{mg} / \mathrm{kg})\end{array}$ & 6 & $\begin{array}{l}\text { Maximum } \\
\text { no. of motor } \\
\text { fits on any } \\
\text { one day }\end{array}$ \\
\hline
\end{tabular}

(The seizure discharges were recorded on a Beckman Accutrace from electrodes implanted in the rats' hippocampi at the operation at which tetanus toxin was injected (see methods). The rats were dosed orally with carbamazepine (or the $0.5 \%$ carboxy-methyl cellulose vehicle) 3 times a day. The values are given \pm SEM).

levels in the order of $1 \cdot 5-2 \mu \mathrm{g} / \mathrm{ml}$ were obtained using this dosing regime. Those rats dosed with $60 \mathrm{mg} / \mathrm{kg}$ of carbamazepine show appreciably higher levels of drug in the plasma than those dosed with $40 \mathrm{mg} / \mathrm{kg}$. Blood levels in both groups fell gradually overnight, and rose again during the daytime following the administration of successive doses of the drug.

Pilot experiment on the effect of carbamazepine on focal epileptic activity in the hippocampus (Experiment 4)

Ten rats received unilateral injections of tetanus toxin into their hippocampi and at the same operation recording electrodes were implanted $0.5 \mathrm{~mm}$ dorsal to the site of toxin injection (see Methods). The behaviour of these rats and their hippocampal EEGs were then recorded continuously for 4 to 7 weeks using a time-lapse split screen video system. Six of these rats were dosed three times daily with carbamazepine $(20 \mathrm{mg} / \mathrm{kg})$ and the four control rats received the "vehicle" only. During the epileptiform syndrome the EEG showed seizure discharges occurring simultaneously within the injected and the uninjected hippocampi at irregular intervals. (These records have been analysed in detail and will be published elsewhere.) Table 3 shows the quantitative analysis of this data and demonstrates that the carbamazepine significantly reduced the proportion of seizure discharges which were associated with motor fits. In this experiment, as before, this dose of carbamazepine did not produce a significant reduction in the total number of motor fits. Carbamazepine did not apparently affect the EEG; there was no reduction in the number of seizure discharges (if anything, an increase).

\section{The effect of carbamazepine on memory}

In these experiments $(1,2,3)$, the effect of chronic treatment with carbamazepine on the memory of control and epileptic rats was tested. All of the animals had been trained on a light-discrimination task in a Y-maze before induction of epilepsy (or control operation). The epileptic rats used for these experiments were those whose fit profiles have already been described in the earlier sections of this paper

iable 4 The effect of carbamazepine (CBZ) on the memories of epileptic and control rats

\begin{tabular}{|c|c|c|c|c|c|c|c|c|c|}
\hline . & $n$ & $\begin{array}{l}\text { Initial trials } \\
\text { to criterion }\end{array}$ & $\begin{array}{l}\text { Trials to } \\
\text { criterion at } \\
\text { retraining }\end{array}$ & & $\begin{array}{l}\text { Saving \% } \\
\text { on trials }\end{array}$ & $\begin{array}{l}\text { Initial errors } \\
\text { to criterion }\end{array}$ & $\begin{array}{l}\text { Errors on } \\
\text { retraining }\end{array}$ & & $\begin{array}{l}\text { Saving \% or } \\
\text { errors }\end{array}$ \\
\hline \multicolumn{10}{|c|}{ Experiment 2: $40 \mathrm{mg} / \mathrm{kg}$} \\
\hline - Control + vehicle & 8 & $35 \cdot 3 \pm 7 \cdot 6$ & $13 \cdot 0 \pm 3 \cdot 3$ & & $40 \cdot 8 \pm 12 \cdot 3$ & $15 \cdot 1 \pm 2 \cdot 5$ & $3 \cdot 0 \pm 0 \cdot 7$ & & $64 \cdot 6 \pm$ \\
\hline Control + CBZ & 8 & $35.9 \pm 7.9$ & $20 \cdot 0 \pm 3 \cdot 0$ & & $19 \cdot 8 \pm 11 \cdot 8$ & $15 \cdot 5 \pm 2 \cdot 9$ & $5 \cdot 0 \pm 0.5$ & & $43 \cdot 6 \pm 8 \cdot 2$ \\
\hline Epileptic + vehicl & 6 & $39 \cdot 7 \pm 10 \cdot 3$ & $43 \cdot 7 \pm 19 \cdot 3$ & & $8 \cdot 7 \pm 22 \cdot 4$ & $16 \cdot 3 \pm 3 \cdot 7$ & $15 \cdot 8 \pm 7 \cdot 8$ & & $19 \cdot 5 \pm 23 \cdot 0$ \\
\hline & \multicolumn{6}{|c|}{ Experiment $3: 60 \mathrm{mg} / \mathrm{kg}$} & $9 \cdot 3 \pm 1 \cdot 2$ & & $14.0 \pm 8.8$ \\
\hline Control + vehicle & 12 & $29 \cdot 5 \pm$ & $16 \cdot 8 \pm$ & \multirow{4}{*}{$p<0.01$} & $33 \cdot 2 \pm 13 \cdot 7$ & $12 \cdot 2 \pm 1 \cdot 4$ & $4 \cdot 5 \pm 1 \cdot 0$ & \multirow{4}{*}{$p<0.05$} & $46 \cdot 5 \pm 10 \cdot 5$ \\
\hline Control + CBZ & 12 & $28 \cdot 0 \pm$ & $20 \cdot 1 \pm 4 \cdot 8$ & & $24 \cdot 1 \pm 13 \cdot 6$ & $11.7 \pm 1.4$ & $7.6 \pm 1.9$ & & $26 \cdot 9 \pm 4 \cdot 2$ \\
\hline Epileptic + vehicl & 11 & $35 \cdot 6 \pm$ & $40 \cdot 2 \pm 7 \cdot 3$ & & $3.7 \pm 9.3$ & $14 \cdot 0 \pm 1 \cdot 1$ & $12.6 \pm 2.6$ & & $17 \cdot 3 \pm 3 \cdot 4$ \\
\hline \multicolumn{8}{|c|}{ Combined Experiments 2 and 3} & & \\
\hline Control + vehicle & 20 & $31 \cdot 8 \pm$ & $15 \cdot 3 \pm$ & \multirow{4}{*}{$\mathrm{p}<0.01$} & $31.9 \pm 9.2$ & $13.4 \pm 1.4$ & $3.9+0.6$ & \multirow{4}{*}{$p<0.01$} & $53.8 \pm$ \\
\hline Control $+\mathrm{CBZ}$ & 20 & $31 \cdot 2 \pm$ & $21 \cdot 0 \pm$ & & $18.4 \pm 9.0$ & $13 \cdot 2 \pm 1 \cdot 5$ & $7 \cdot 5 \pm 1 \cdot 3$ & & $33.6 \pm 8.2$ \\
\hline Epileptic + vehicl & 17 & $37 \cdot 1 \pm$ & $41 \cdot 4 \pm$ & & $5 \cdot 5 \pm 10 \cdot 0$ & $14.8 \pm 1.5$ & $13 \cdot 8 \pm 3 \cdot 2$ & & $18 \cdot 1 \pm 10 \cdot 5$ \\
\hline Epileptic + CBZ & 16 & $31.4 \pm$ & $19 \cdot 6 \pm$ & & $31 \cdot 1 \pm 10 \cdot 2$ & $14 \cdot 1 \pm 1 \cdot 6$ & $7 \cdot 0 \pm 1 \cdot 3$ & & $38 \cdot 8 \pm 10 \cdot 0$ \\
\hline
\end{tabular}

Note: The epileptic rats are the same animals as those whose epileptic history is given in table 2 and fig. 2. The carbamazepine was given orally, 3 times daily, for approximately 4 weeks after the first motor fit. The rats were trained on the light-discrimination task one week before operation and re-trained 7 weeks after operation. The values are given \pm standard error of the mean. The $p$ values are derived from two-way analysis of variance and $t$-tests. 
(Experiments 2 and 3). In all, 73 rats were used which had been trained in the Y-maze, one week later had been stereotaxically injected with tetanus toxin or buffer (controls) bilaterally into their hippocampi, and seven weeks after that, had their memories tested for the original learning task.

Table 4 shows the initial and re-training scores of the rats in the two experiments where they were treated with $40 \mathrm{mg} / \mathrm{kg}$ (three times daily) or $60 \mathrm{mg} /$ $\mathrm{kg}$ respectively. On all measures of memory the epileptic animals had significantly poorer memories than their untreated controls. In both experiments there was a (non-significant) trend for carbamazepine to impair the memories of the control animals. At both doses, the carbamazepine improved the memories of the epileptic rats. With the lower dose of drug this was only apparent on the error and trial scores at re-training and did not reach statistical significance. With the higher dosage, the carbamazepine successfully counteracted the memory loss and the scores for the treated unimals were now not significantly different from those of nonepileptic control rats.

Since the scores for control rats in these experiments were not significantly different from each other and since the dose effect was small, the two experiments have been combined. Analysis of variance then gives a significant improvement of the epileptic animals' memories by carbamazepine, both on trials to criterion (df $3,69, F=5.71$ ) and errors to criterion (df $3,69, F=5 \cdot 29), p<0.01$ ).

\section{Discussion}

Carbamazepine, administered three times daily, at a dosage of 20,40 and $60 \mathrm{mg} / \mathrm{kg}$ had an antiepileptic effect in the tetanus toxin-induced hippocampal epilepsy. With the two lower doses, the only statistically significant effect was to reduce the maximum number of overt fits occurring on any one day. With the highest dose, there was also a significant reduction in the total number of overt fits that occurred throughout the syndrome. The separate experiments were not originally intended to constitute a doseresponse curve; the strategy was to try to find a dose with a reliable antiepileptic effect. There are differences in the details of the individual experiments and it is therefore not surprising that a statistically significant dose-effect does not emerge when the three are combined and the appropriate nested design for the analysis of variance is carried out. Combining the groups does however produce a highly significant antiepileptic effect of the drug on both total fits and maximum number of fits on one day.

Daily handling of the rats showed that this anti- epileptic effect occurred without any obvious adverse effects such as sedation. Carbamazepine is considered to be a suitable drug for the treatment of complex partial seizures. In two of the three double-blind studies $\mathrm{v}$ placebo reviewed by Sillanpaa ${ }^{17-20}$ carbamazepine was reported to reduce psychomotor attacks. In studies where carbamazepine has been compared with phenytoin, it has been shown to be equally anticonvulsant and to produce fewer side effects. ${ }^{11-13}$ Our finding of a reduction in fits by carbamazepine in the epileptic rats further validates the usefulness of this model of complex partial seizures.

The memory impairment produced by the epilepsy was improved by the carbamazepine in the experiment (3) in which the frequency of overt fits was significantly reduced. In Experiment 2, the small improvement in memory did not reach statistical significance. It may be relevant that in Experiment 3 the carbamazepine reduced the fit frequency significantly at night as well as during the day, whereas in Experiment 2 the reduction in fit frequency occurred mainly in the day. When the results from these two experiments are combined, then carbamazepine treatment is shown to have a highly significant improving effect on the memory which has been impaired by the epilepsy.

From the first clinical studies with carbamazepine, it has been observed that the drug, while being ane effective antiepileptic, does not normalise the EEG. ${ }^{21}$ Our preliminary results with animals is which the EEG has been continuously recorded fot $\overrightarrow{0}$ weeks, suggest that in the epileptic rats the same is? or true. In the pilot study, $20 \mathrm{mg} / \mathrm{kg}$ carbamazepine produced some (but not statistically significant) reduction in overt fits while causing no reduction (if anything an increase) in the number of seizure discharges recorded from the hippocampus. This meant that the administration of the drug led to a significant reduction in the proportion of the seizure discharges which lead to overt fits. The results of this pilot study suggests therefore that the carbamazepine (at least at this low dose) acts not on the epileptic focus itself but to stop the spread of seizure activity into other areas of the brain. These results may be relevant to the question of whether the memory deficit that the hippocampal epilepsy produces results directly from the epileptic focus in the hippocampus (or possibly directly from the local action of the toxin), or from the spread of this electrical activity leading to overt fits. It appears that it may be the spread of the seizure activity rather than the local abnormality which is responsible for the enduring memory deficit.

The finding that carbamazepine does not itself significantly impair or improve memory for the 
Y-maze tasks in the control rats (and this has recently been confirmed for all three doses; Ian Doughty, 1984 unpublished) supports the idea that it is an interaction between the drug and fits, not merely some separate effect of the drug, which is responsible for this anti-amnesic effect of carbamazepine. It has often been suggested " that carbamazepine may have a psychotropic effect in epileptic patients. It has however also been argued that such an effect is only apparent and results from the replacement of drugs which are actively deleterious by carbamazepine which does not have deleterious effects. While the present experiments did not show any evidence for a psychotropic effect of carbamazepine in control rats, the improvement of memory in the epileptic rats could of course be described as psychotropic. We have also found a further type of behavioural improvement which carbamazepine treatment produces specifically in epileptic rats. During the 2 or 3 weeks after our rats have stopped having motor fits but still probably have epileptiform abnormalities in their EEGs, ${ }^{4}$ they are hyper-reactive. Epileptic rats which had received carbamazepine during the 4 weeks of overt epilepsy are less hyper-reactive at this stage than their epileptic controls treated with only the vehicle for carbamazepine. ${ }^{22}$

The plasma levels of the carbamazepine which we found in our rats were around $2 \mu \mathrm{g} / \mathrm{ml}$ which is at the lower end of the human therapeutic range. ${ }^{23}$ However, in view of the finding ${ }^{24}$ that in rats dosed with carbamazepine the plasma level of the pharmacologically active epoxide metabolite is equal to that of carbamazepine, our values (of carbamazepine itself) presumably represent only half of the level of active substance. In humans, apparently, only about $15 \%$ is present as the epoxide and therefore our values for carbamazepine itself in the rat can presumably be nearly doubled to make them comparable with human values. This then suggests that the fits in our animal model are about as sensitive to carbamazepine as are the comparable fits in man. This would therefore support the possibility that our findings could be relevant to clinical epilepsy.

We are grateful to Professor GH Glaser and Dr C Ounsted for helpful discussions, to Jennie Tanner for invaluable help with the statistical treatment of data, and Dr John Keenan for carrying out the assays of carbamazepine and to Dr PCB MacKinnon for teaching us to cannulate rats. We thank the British Epilepsy Fund, CIBA-GEIGY Limited and St Hilda's College, Oxford, for financial support. $\mathrm{CH}$ was in receipt of a SERC CASE award.

\section{References}

' Mellanby J, Green J. How does tetanus toxin act? Neuroscience 1981;6:281-300.

${ }^{2}$ Collingridge GL, Thompson P, Davies J, Mellanby J. In vitro effect of tetanus toxin on GABA release from rat hippocampal slices. J Neurochem 1981;37:1039-41.

${ }^{3}$ Mellanby J, George G, Robinson A, Thompson PA. Epileptiform syndrome in rats produced by injecting tetanus toxin into the hippocampus. $J$ Neurol Neurosurg Psychiatry 1977;40:404-14.

${ }^{4}$ Mellanby J, Strawbridge P, Collingridge GI, et al. Behavioural correlates of an experimental hippocampal epileptiform syndrome in rats. $J$ Neurol Neurosurg Psychiatry 1981;44:1084-93.

${ }^{5}$ George G, Mellanby J. Memory deficits in an experimental hippocampal syndrome in rats. Exp Neurol 1982;75:678-89.

- Mellanby J, Renshaw M, Cracknell H, Rands G, Thompson P. Long-term impairment of learning ability in rats after an experimental hippocampal epileptiform syndrome. Exp Neurol 1982;75:690-9.

' Brown SW, Reynolds EH. Cognitive impairments in epileptic patients. In: Reynolds EH, Trimble MR, eds. Epilepsy and Psychiatry. London: Churchill Livingstone 1981:147-64.

8 Trimble MR, Thompson PJ. Memory, anticonvulsant drugs and seizures. Acta Neurol Scand Supp 89 1980;64:31-41.

${ }^{9}$ Mellanby J, Hawkins CA, Wilks L. The relationship between seizures and amnesia in experimental epilepsy. Acta Neurol Scand (in press).

${ }^{10}$ Glaser GH. Epilepsy: Neuropsychological effects. In: Arieti S, ed. American Handbook of Psychiatry, Vol. 4. New York: Basic Books Inc. 1975:314-55.

" Penry JK, Daly DD, eds. Complex Partial Seizures and their Treatment. Advances in Neurology Vol. II. New York: Raven Press, 1975.

${ }^{12}$ Simonson $\mathbf{N}$, Zander Olson $\mathrm{P}$, Kuhl V, Lund $\mathbf{M}$, Weldelboer J. A comparative controlled study between carbamazepine and diphenyl-hydantoin in psychomotor epilepsy. Epilepsia 1976;17:169-76.

${ }^{13}$ Troupin A, Olemann LM, Halpen L, et al. Carbamazepine-a double blind comparison with phenytoin. Neurology (Minneap) 1977;27:511-9.

${ }^{14}$ Mellanby J, Mellanby H, Pope D, van Heyningen WE. Ganglioside as a prophylactic agent in experimental tetanus in mice. J Gen Microbiol 1968;54:161.

${ }^{15}$ George G, Mellanby J. A further study of the effect of physostigmine on memory in rats. Brain Res 1974;81:133-44.

${ }^{16}$ de Groot J. The Rat Forebrain in Stereotaxic Coordinates. Amsterdam: N.V. Noord-Hollansche Vitgevers Maatschappis 1967.

17 Silanpaa S. Clinical antiepileptic effect. Acta Neurol Scand (Suppl.) 1981;88:69-97.

is Pryse-Phillips WEM, Jeavons PM. Effect of carbamazepine on the electroencephalographic and ward behaviour of patients with chronic epilepsy. Epilepsia 1970;11:263-73.

19 Rodin EA, Rim CS, Rennick PM. The effects of carbamazepine on patients with psychomotor epilepsy. 
Results of a double-blind study. Epilepsia 1974; 15:547-61.

${ }^{20}$ Kutt H, Solomon G, Wasterlain C, Petersen H, Louis S, Carruthers R. Carbamazepine in difficult to control epileptic outpatients. Acta Neurol Scand (Suppl.) 1975; 60:27-32.

${ }^{21}$ Wilkus RJ, Dodrill CB, Troupin AS. Carbamazepine and the electroencephalogram of epileptics: A double-blind study in comparison to phenytoin. Epilepsia 1978;19:283-91.

${ }^{22}$ Mellanby J, Hawkins CA, Baillie-Hamilton S, Bourne
M, Shepherd L, Stroud C. (1985). In: Trimble MR, ed. Temporal Lobe Epilepy. John Wiley (in press).

${ }^{23}$ Cereghino JJ. Carbamazepine. Relation of plasma concentration to seizure control. In: Woodbury DM, Penry JK, Pippenger CE, eds. Antiepileptic Drugs. New York: Raven Press 1982:507-19.

${ }^{24}$ Faigle JW, Feldmann KF. Carbamazepine. Biotransformation. In: Woodbury DM, Penry JK, Pippenger, eds. Antiepileptic Drugs. New York: Raven Press 1982:483-95. 